\title{
And if we had to do it all over again, would we send medical students to the emergency departments during a pandemic? Lessons learned from the COVID-19 outbreak
}

\author{
Thierry Pelaccia ${ }^{1,2}$ (1) - Jean Sibilia ${ }^{3}$ (D) Élodie Fels ${ }^{3} \cdot$ Lucas Gauer $^{4} \cdot$ Audrey Musanda $^{3} \cdot$ François Severac $^{5}$ (D) \\ Milena Abbiati ${ }^{6,7}$ (D)
}

Received: 25 October 2020 / Accepted: 31 December 2020 / Published online: 16 January 2021

(c) Società Italiana di Medicina Interna (SIMI) 2021

\begin{abstract}
The COVID-19 pandemic has led to increased staffing needs in emergency departments. The question quickly arose as to whether it was appropriate to offer medical students the opportunity to assist this staff. The dilemma stems in part from the potential impact on their psychological well-being as well as their academic and clinical performances. We sought to determine the level of anxiety of medical students during the COVID-19 outbreak, and whether it was higher among the students who chose to return to the clinical setting, especially in first-line units (i.e., emergency departments and resuscitation units). In May 2020, 1180/1502 (78.5\%) undergraduate medical students at Strasbourg Medical School (France) completed a questionnaire assessing their anxiety and clinical experience. A 2018 cohort of undergraduate medical students served as the baseline. The 2020 COVID cohort had higher rates of anxiety than the 2018 cohort. This difference was specifically observed in the students who chose not to return to the clinical setting during the crisis $(N=684,59 \%)$. At linear regression, the main factors associated with anxiety were gender $(p<0.005)$ and perceived clinical activity personal conditions $(p<0.001)$. Employment site, including COVID first-line units, was not correlated with anxiety. Working in the clinical setting during the COVID-19 outbreak is not a risk factor for anxiety in medical students. Instead, it is an active coping strategy, suggesting that there are no barriers to allowing students to return to clinical settings during a pandemic, including first-line units, in terms of their psychological well-being.
\end{abstract}

Keywords Anxiety $\cdot$ COVID-19 $\cdot$ Clinical placements $\cdot$ Coping

Thierry Pelaccia

pelaccia@unistra.fr

1 Prehospital Emergency Care Service (SAMU 67), Strasbourg University Hospital, Strasbourg, France

2 Centre for Training and Research in Health Sciences Education (CFRPS), Faculty of Medicine, University of Strasbourg, Strasbourg, France

3 Faculty of Medicine, University of Strasbourg, Strasbourg, France

4 Strasbourg University Hospital, 1 place de l'Hôpital, Strasbourg, France

5 Public Health Service, GMRC, Strasbourg University Hospital, Strasbourg, France

6 Institute of Legal Psychiatry, Lausanne University Hospitals, Lausanne, Switzerland

7 Unit of Development and Research (UDREM), Faculty of Medicine, University of Geneva, Geneva, Switzerland

\section{Introduction}

The coronavirus 2019 (COVID-19) outbreak has led to a sudden and considerable increase in human needs in acute hospital wards, particularly in emergency departments. The health and academic authorities were confronted early on with the issue of whether or not to allow undergraduate students to assist healthcare professionals with COVID-19 patients [1]. In the United States, Canada, United Kingdom, and France, as in many other countries, the authorities also decided to allow undergraduate students to return to the clinical setting on a voluntary basis [2-5].

Yet, the debate about whether or not to allocate medical students to COVID-19 first-line units is still ongoing. It is notably underpinned by psychological concerns, particularly related to the anxiety-provoking nature of the situation [6]. Anxiety is a natural emotional reaction to a stressful situation characterized by feelings of tension, worry, or 
apprehension, which function is to alert to potential threats, allowing the person to evaluate and respond in appropriate ways [7]. In case of inadequate response, high and persistent anxiety levels can negatively impact students' academic performance, increase the risk of dropping out, decrease empathy, and lead to over-consumption of alcohol and drugs $[8,9]$. Furthermore, anxious undergraduate students often become anxious residents and then anxious practitioners, potentially impairing performance and increasing errors $[10$, $11]$.

The COVID-19 pandemic is commonly reported as impacting anxiety among medical students owing to the disruption of academic and clinical activities, and to the redeployment of some students into COVID-related clinical activities [12-15]. Two COVID-19-related studies found that the rates of medical students showing signs of anxiety ranged from 25 to $50 \%[12,16]$. Beyond the wide range of the estimate, these studies did not examine the role of clinical activity, especially in COVID-19 first-line units, even though it could be a major determinant of anxiety in this type of event $[17,18]$. They are also criticized for the lack of pre-COVID-19 comparison points [19].

Public health crisis related to emerging infections will become increasingly common in the coming years [20]. It is, therefore, crucial that health and academic authorities use the COVID-19 experience to improve their response capability. The aim of this study was to examine the clinical activity of undergraduate medical students in a COVID-19 hotspot and its association with anxiety. With more than 65,000 dead at the beginning of January, 2021, France is the seventh most affected country. Strasbourg and the Great East region were the initial epicenter and the most intense spot of COVID-19 circulation in France. We sought to determine whether the COVID-19 outbreak made undergraduate medical students anxious, and in particular whether allowing medical students to return to the clinical setting in COVID-19 first-line units was a risk factor for anxiety.

\section{Methods}

\section{Study design and sample}

Between May 7 and 17, 2020, we conducted a multi-institutional cross-sectional study. We recruited all undergraduate students from Strasbourg Medical School in three training stages: 2nd and 3rd year (preclinical, $n=302$ and $n=303$, respectively), 4th and 5th year (clinical, $n=302$ and $n=300$, respectively), and 6th year (graduating, with a high-stake final exam in July, $n=302$ ) to complete an online survey. First-year students $(n=1580)$ were excluded since in France, they are in a selection year. Prior to the COVID-19 outbreak, all of them were allocated to clinical activities on a part-time basis. Those who chose to return working during the pandemic (referred to as "employed students") were affected in a COVID-related clinical setting according to need, respecting their wishes. Participation in the study was elective, and responses were anonymized. Participants were informed that their completion of the questionnaire indicated their consent to participate in the study. We sent two reminders, at 4- and 8-day intervals after the first distribution, respectively, and student representatives sent reminders on social networks. Ethical approval has been granted by the Institutional Review Board of Strasbourg Medical School.

To address whether medical students were more anxious during the COVID-19 outbreak, we compared the current data with those from a survey conducted from March to May 2018 among all Strasbourg Medical School undergraduates $(N=1471$, return rate $86 \%)$. The procedure was similar, with no significant changes in learning context.

\section{Measures and survey development}

The survey covered demographics (age, gender, year of study) and employment status during the COVID-19 outbreak (allocated to a health facility [employed]; not allocated [unemployed]) as well as clinical experience and anxiety. Clinical experience included employment site (COVID first-line units, i.e., emergency departments and resuscitation units; COVID medical units, i.e., other departments), primary role (usual role, i.e., role usually performed by a medical student; unusual role, i.e., role usually performed by other health professionals), supervision (yes/no), specific training (yes/no), development of new skills (yes/no), and students' perceptions about their clinical experience.

Since there is no scale to explore perceptions about the clinical experience in times of crisis, we created a new scale-referred to as the "Crisis Experience Rating Scale" (CERS-7)—following the steps described by Artino et al. [21] and Cook et al. [22] for validation. The CERS-7 items, rated on a six-point Likert scale, were retrieved from the instructions of the health and academic authorities regarding the mobilization of medical students during the health crisis $[2,4,5]$. Item content validation was undertaken by an interprofessional panel of ten persons. Principal component analysis (Kaiser-Meyer-Olkin statistic 0.76, $p<0.001,67 \%$ of variance explained) aggregated these items into two factors-factor 1: "CERS-Professional Experience (PROFEX)" subscale, $41 \%$ of variance explained (perceived level of preparedness, perceived competence to perform tasks, perceived helpfulness in assisting healthcare professionals treat patients, perceived level of team integration; Cronbach's alpha $=0.82$ ), and factor 2: "CERS-Personal Experience (PERSEX)" subscale, 26\% of variance explained (perceived insecurity about infectious risk, perceived workload, sleep deprivation; Cronbach's alpha $=0.72$ ). The tool's overall 
scale (CERS-7 total) Cronbach's alpha was 0.75. We used the PROFEX $(\min =4, \max =24)$ and PERSEX $(\min =3$, $\max =18$ ) subscales. The higher the score, the more positively the crisis experience was perceived.

For the outcome variable (anxiety), surveys for both the current and 2018 samples were based on the State-Trait Anxiety Inventory (STAI-Y), widely used to measure anxiety in medical students $[11,24]$. We assessed state anxiety using the validated French version of the state anxiety subscale (STAI-A) [23]. It consists of 20 items scored on a four-point Likert scale $(1=$ yes to $4=$ no). The total score (STAI-A Total score) ranges from 20 to 80 with females typically scoring higher than males. The higher the score, the higher the anxiety level. The STAI-A Total scores can be categorized into a three-point cutoff to detect clinically significant symptoms: below 55 (average anxiety), 56-65 (high anxiety), and above 65 (severe anxiety). Persistent high anxiety may require psychological counseling, while persistent severe anxiety must require psychological counseling. Our overall Cronbach's alpha $(\alpha=0.95)$ confirmed STAI-A's excellent internal reliability.

For structured scales, more than $10 \%$ of non-response led to participant exclusion.

\section{Data analysis}

All analyses were performed with SPSS version 24 (IBM Corp., Armonk, NY, USA). We set statistical significance at $p<0.05$ together with 95\% confidence intervals (CI) for all inferential tests. We used supporting data analysis and wave analysis to assess non-response bias [24]. We used standard descriptive statistics and analysis of variance or chi-square tests for univariate comparisons to characterize and make comparisons between employed and unemployed students as well as between employment conditions and gender. We used chi-square tests for the comparative analyses with the 2018 survey on STAI-A three-point cutoff frequencies. Adjusted $p$ values for multiple comparisons were calculated using the false discovery rate (fdr) method [25]. We used multivariate analysis of variance (MANOVA) to compare anxiety by employment status, employment sites, and gender. We used linear regression analyses (mean differences) to examine correlates of STAI-A Total score in employed students. We included variables following their clinical relevance [26]. We assessed the normality of residuals graphically using quantile-quantile plots and the Shapiro-Wilk test. We tested collinearity using the variance inlation factor (VIF) 186 and ensuring that no variable had a VIF greater than 2 [22].

\section{Results}

Of the 1180 respondents ( $78.5 \%$ response rate), 1165 with complete data on all variables constituted our analytic sample. Of the sample, $760(65.2 \%)$ were females, with no significant differences between training stages. Mean (standard deviation $( \pm S D))$ age was 23 years $(S D \pm 6.3)$. The gender and age distribution mirrored that of national and local (Strasbourg) medical school data [27]. The results of a wave analysis comparing the gender and age characteristics of last-call participants with others showed no difference between the two groups.

Of the 481 (41.3\%) employed students, 315 (64.9\%) were females, which corresponds to the gender ratio of unemployed students. The majority were clinical students (375, 78.0\%). Table 1 compares the demographic characteristics of employed and unemployed students.

Students had been allocated to 11 hospitals, which included 6 emergency departments and 4 resuscitation units. About half of the students had been allocated to first-line units $(243,50.5 \%)$. A majority worked under supervision (416, 86.5\%), and two-thirds reported that they received specific training and developed new skills. Overall, students perceived their professional and personal clinical experience

Table 1 Demographics of employed and unemployed students

\begin{tabular}{lllll}
\hline & $\begin{array}{l}\text { All students } \\
(n=1165)\end{array}$ & $\begin{array}{l}\text { Employed } \\
(n=481)\end{array}$ & $\begin{array}{l}\text { Unemployed } \\
(n=684)\end{array}$ & $\begin{array}{l}\text { Mean difference between } \\
\text { employed and unemployed [95\% } \\
\text { CI] }\end{array}$ \\
\hline $\begin{array}{llll}\text { Gender, } n(\%) \\
\text { Female }\end{array}$ & $760(65.2 \%)$ & $315(41.4 \%)$ & $445(58.6 \%)$ & $-17.2[-18.1 ;-16.3]$ \\
Male & $405(34.8 \%)$ & $166(41.0 \%)$ & $239(59.0 \%)$ & $-18.0[-19.2 ;-16.7]$ \\
Age, mean/median $( \pm$ SD [range]) & & & \\
Age & $22.8 / 22( \pm 6.3[39-18])$ & $23.4 / 23( \pm 5.6[39-19])$ & $22.3 / 22( \pm 6.3[37-18])$ & $-0.9[1.0 ; 1.1]$ \\
$\begin{array}{l}\text { Training stage } \\
\text { Preclinical }\end{array}$ & $531(45.6 \%)$ & $66(12.4 \%)$ & $465(87.6 \%)$ & $-75.2[-80.2 ;-70.2]$ \\
$\begin{array}{l}\text { Clinical } \\
\text { Graduating }\end{array}$ & $471(40.4 \%)$ & $375(79.6 \%)$ & $96(20.4 \%)$ & $59.2[63.2 ; 55.2]$ \\
\hline
\end{tabular}


as moderately positive. All significant differences between the groups were $p<0.001$. There were no significant differences by gender in any of these variables. Table 2 shows students' employment sites and clinical experience.

Of the 531 preclinical respondents in the analytic sample, $145(27.3 \%)$ exceeded the average STAI-A anxiety cutoff point versus 36 of 467 (7.7\%) in 2018. Similarly, of the 163 graduating respondents in the analytic sample, 60 (36.8\%) exceeded the average STAI-A anxiety cutoff versus 32 of $246(12.9 \%)$ in 2018 . All $p$ values between these groups were $<0.001$. Clinical students showed a similar prevalence

Table 2 Employment sites and clinical experience characteristics

\begin{tabular}{lc}
\hline & Employed \\
\hline & $(n=481)$ \\
Employment site, $n(\%)$ & $243(50.5 \%)$ \\
COVID-19 first-line units & $238(49.5 \%)$ \\
COVID-19 medical units & \\
Clinical experience-real conditions, $n(\%)$ & $265(55.1 \%)$ \\
Primary role (usual) & $416(86.5 \%)$ \\
Supervision (yes) & $291(60.5 \%)$ \\
Specific training (yes) & $317(65.9 \%)$ \\
Development of new skills (yes) & $14.2 / 16( \pm 6.5[1 ; 24])$ \\
Clinical experience-perceived conditions, M/m $( \pm$ SD [range]) & $12.4 / 14( \pm 4.7[1 ; 18])$ \\
CERS-PROFEX & \\
CERS-PERSEX &
\end{tabular}

SD: standard deviation; CERS-PROFEX: Crisis Experience Rating Scale-Professional Experience subscale; CERS-PERSEX: Crisis Experience Rating Scale-Personal Experience subscale, M: mean; m: median rate as the 2018 sample. Table 3 shows the anxiety prevalence rate by STAI-A cutoff points (95\% CI) compared to the 2018 sample.

Overall, anxiety was higher in unemployed (mean difference (MD) 3.4; 95\% CI 1.5; 5.5, $p<0.001$ ) and female students (MD 5.8; 95\% CI 3.7; 7.8, $p<0.001$ ). There was no significant difference by employment sites though anxiety was still higher in employed females than males (MD 4.3; $95 \%$ CI $1.0 ; 6.8, p<0.001)$. MANOVAs showed no interaction effects between activity status or employment site and gender. Figure 1 shows the variation in mean (95\% CI) anxiety for employed and unemployed students, males and females, as well as for employment sites stratified by gender.

Answering our research question (Table 4), employment in COVID-19 first-line units was not correlated with anxiety, while being female ( $\mathrm{MD}=3.3$; 95\% CI 1.0; 5.7, $p<0.005)$, negative CERS-PROFEX (MD $=-0.2$ : $95 \% \mathrm{CI}-0.3 ;-0.1$, $p<0.030$ ), and negative CERS-PERSEX (MD $=-0.5 ; 95 \%$ CI $-0.7 ;-0.2, p<0.001)$ were. On the contrary, none of the clinical experience real conditions were correlated with anxiety.

\section{Discussion}

To our knowledge, our study is the first to compare the anxiety of undergraduate medical students who were allocated to COVID-19 first-line units with that of students who chose not to return to the clinical setting, with a baseline of undergraduate student anxiety prior to COVID-19. Our work revealed that the employed students were less
Table 3 Comparison of anxiety between the 2020 cohort and the 2018 cohort

\begin{tabular}{|c|c|c|c|c|c|c|}
\hline STAI-A Total score & \multicolumn{2}{|l|}{2020 cohort } & \multicolumn{2}{|l|}{2018 cohort } & $p$ & Adjusted $p$ \\
\hline \multicolumn{7}{|c|}{ Undergraduate $N(\%) / 95 \% \mathrm{CI}$} \\
\hline All & $N=1165$ & & $N=1252$ & & & \\
\hline$<55$ & $901(77.3)$ & $74.8 ; 79.7$ & $1141(98.2)$ & $89.4 ; 92.6$ & $<0.001$ & $<0.001$ \\
\hline $55-65$ & $178(15.3)$ & $13.3 ; 17.4$ & $85(0.7)$ & $5.4 ; 8.3$ & & \\
\hline$>66$ & $86(7.4)$ & $5.9 ; 9.0$ & $26(0.2)$ & $1.4 ; 3.0$ & & \\
\hline Preclinical & $n=531$ & & $n=467$ & & & \\
\hline$<55$ & $386(72.7)$ & $68.7 ; 76.4$ & $431(92.3)$ & $89.5 ; 94.5$ & $<0.001$ & $<0.001$ \\
\hline $55-65$ & $93(17.5)$ & $14.4 ; 21.0$ & $27(5.8)$ & $3.8 ; 8.3$ & & \\
\hline$>66$ & $52(9.8)$ & $7.4 ; 12.6$ & $9(1.9)$ & $0.9 ; 3.6$ & & \\
\hline Clinical & $n=471$ & & $n=536$ & & & \\
\hline$<55$ & $412(87.5)$ & $84.1 ; 90.3$ & 493 (91.9) & $89.3 ; 94.1$ & .134 & .246 \\
\hline $55-65$ & $51(10.8)$ & $8.2 ; 14.0$ & $34(6.3)$ & $4.4 ; 8.7$ & & \\
\hline$>66$ & $8(1.7)$ & $0.7 ; 3.3$ & $9(1.6)$ & $0.7 ; 3.1$ & & \\
\hline Graduating & $n=163$ & & $n=249$ & & & \\
\hline$<55$ & $103(63.2)$ & $55.3 ; 70.6$ & $217(87.1)$ & $82.3 ; 91.0$ & $<0.001$ & $<0.001$ \\
\hline $55-65$ & $34(20.9)$ & $14.8 ; 27.9$ & $24(9.7)$ & $13.1 ; 23.0$ & & \\
\hline$>66$ & $26(15.9)$ & $10.7 ; 22.5$ & $8(3.2)$ & $1.4 ; 6.2$ & & \\
\hline
\end{tabular}

CI: confidence interval 

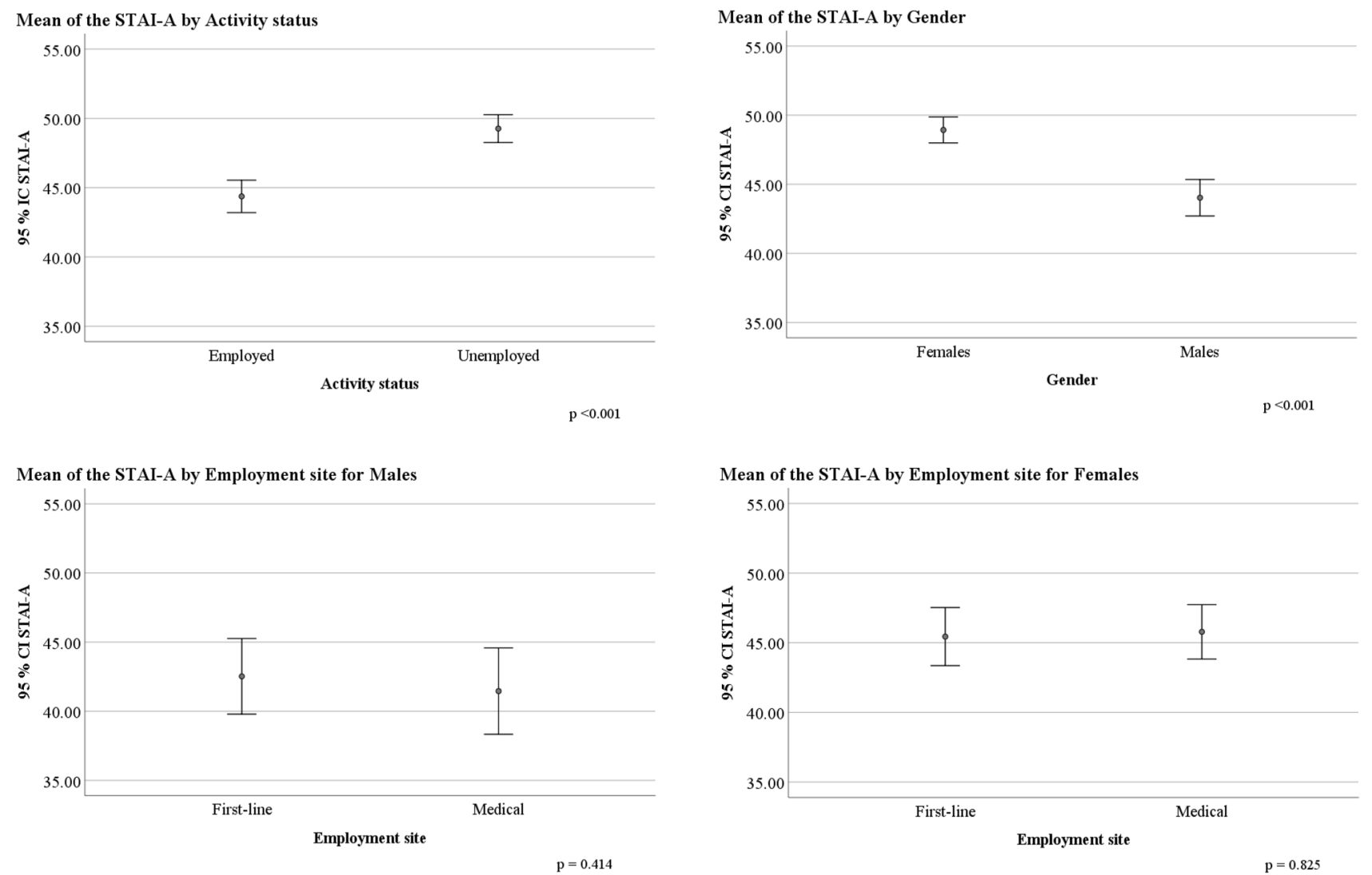

Fig. 1 Plots of mean $(95 \% \mathrm{CI})$ anxiety scores (STAI-A) by gender, activity status, and employment site stratified by gender

Table 4 Linear regression analysis of mean difference $[95 \% \mathrm{CI}]$ in demographic, employment site, and clinical experience variables in relation to anxiety in employed students

\begin{tabular}{lll}
\hline Variable & MD $[95 \% \mathrm{CI}]$ & $p$ \\
\hline & Employed & \\
Gender (female) & $3.3[1.0 ; 5.7]$ & $<0.005$ \\
Employment sites (first line) & $-0.2[-3.2 ; 3.1]$ & .889 \\
Primary role (usual) & $-0.1[-3.4 ; 1.5]$ & .435 \\
Specific training (yes) & $1.5[-0.8 ; 3.8]$ & .198 \\
Supervision (yes) & $1.5[-1.9 ; 4.8]$ & .382 \\
Development of new skills (yes) & $0.5[-2.0 ; 2.9]$ & .691 \\
CERS-PROFEX & $-0.2[-0.3 ;-0.1]$ & $<0.030$ \\
CERS-PERSEX & $-0.5[-0.7 ;-0.2]$ & $<0.001$ \\
\hline
\end{tabular}

MD: mean difference; CI: confidence interval; CERS-PROFEX: Crisis Experience Rating Scale-Professional Experience subscale; CERS-PERSEX: Crisis Experience Rating Scale-Personal Experience subscale

anxious than the unemployed students, regardless of their employment site. We also showed that engaging students in COVIID-19 first-line units was not a risk factor for anxiety, as opposed to gender, and negative clinical experience perceived conditions.
Increasing attention is being paid to medical students' well-being. In many countries, national authorities have issued recommendations to identify and prevent psychological disorders, including anxiety, in their students [28-31]. Although many personal factors have been identified as anxiety generators, academic and clinical stressors are frequently questioned [32]. The COVID-19 outbreak has characteristics of both. We found that the 2020 cohort was more anxious than the 2018 cohort, with an average increase of $14 \%$ and $7 \%$ in students with high and severe anxiety, respectively. These rates do not differ from those measured in the general population in the COVID-19 context [33]. They are also within the overall average measured in medical students outside of the COVID-19 outbreak [34]. This suggests that the impact of the pandemic on student well-being is real, but is not as significant as one might spontaneously think. Our results also confirm the well-known effect of gender, with females showing higher anxiety than males [10]. However, we provided as a result its lack of correlation with activity status and employment sites during the COVID-19 outbreak, as females were exposed to front-line conditions as much as males. This suggests that there is no gender difference in choosing to return to clinical activities during a pandemic. 
Moreover, we provided findings supporting the hypothesis that employment during the COVID-19 outbreak was not a risk factor for anxiety. The difference in anxiety observed in our population concerns mainly unemployed students. Coping refers to the strategies utilized when faced with a stressor [35]. We suggest that choosing to return to the clinical setting during an outbreak is an active coping strategy, which is an adaptive way to face anxiety [36-39]. Conversely, students choosing not to return to clinical activities used less appropriate coping strategies to reduce their COVID-19-related anxiety. They may have favored avoidance strategies, which have a negative impact on anxiety [40, 41], particularly among healthcare professionals and medical students [37, 42, 43]. Those explanations support the potential benefits of implementing interventions focused on the enhancement of adaptive coping, e.g., positive reinterpretation, which is viewing a situation as an opportunity to learn new skills. These strategies could encourage students and other health professionals to return or be reallocated to clinical settings during a pandemic, and thus respond to increased staffing needs, especially in settings where the need is greatest, such as emergency departments [36, 37].

One limitation of our study is the assessment of only one of the several psychological consequences of the current health crisis, that is, anxiety. While increased anxiety is frequently observed after such events, particularly among healthcare workers, other problems have been described, including anger, depression, and suicide [44, 45]. Another limitation is the inclusion of limited protective/risk factors, essentially concerning clinical experience. Other personal and interpersonal protective/risk factors should be considered. Moreover, our study compared two partially different cohorts with a 2-year interval. This limitation must be put into perspective considering that both surveys were conducted at the same time of the year, that no major changes in the curriculum took place, and that the response rate was high in both cohorts. Finally, we did not measure student anxiety at the very beginning of the health crisis. Therefore, we cannot rule out the possibility that students who decided to work in a clinical setting were those with the lowest initial anxiety levels. However, this limitation does not call into question the relevance of our results. First, because once students become involved on a voluntary basis, their initial level of anxiety may legitimately be a factor in whether or not they become involved. Second, and assuming a lower initial level of anxiety, our data tend to show that being employed did not generate an anxiety-producing effect in these students. Finally, because, in general, it is more relevant to measure anxiety at the end of a phenomenon to determine whether adaptive mechanisms were deployed. Anxiety state is indeed variable over time (although correlated with trait anxiety, implying that people of an anxious nature are more likely to increase their anxiety contextually than others). It is, therefore, possible that students' anxiety may have been lower or higher at some point during the crisis (at the beginning or peak, for example), but when it is at the level where we measured it at the end of the crisis, this means that the coping strategies mobilized by the students were effective, which is the most important thing.

\section{Conclusions}

At the peak of the COVID-19 pandemic, 194 countries closed their universities, affecting more than $90 \%$ of the world's student population, and exposing hospitals to a brutal workforce shortage [46]. Our results legitimize recommendations made in most countries to deal with this unprecedented situation, i.e., mobilizing only students in places where their presence is useful, and only if they are voluntary. However, our findings should lead institutions to question the level of mobilization of undergraduate medical students. They suggest that clinical activities, including in first-line units, are not anxiety risk factors. Therefore, there is no obstacle to mobilizing students in high-risk settings, as long as there is a need, their involvement is voluntary, they are and feel protected, and that supervisors remain vigilant regarding the risk of professional exhaustion.

Acknowledgements The authors wish to thank Andréa Mignerey, Deputy Director of the Medical Affairs Department at Strasbourg University Hospital, for her help in identifying assignments for students in clinical settings. The authors also thank the undergraduate students' representatives for their assistance in administering the survey.

Author contributions TP contributed significantly to the design of the study and to data acquisition and interpretation. He drafted the initial version of the manuscript and oversaw revisions. JS contributed to the design of the study and to data interpretation. He reviewed manuscript drafts. EF contributed to the design of the study and to data acquisition and interpretation. She reviewed manuscript drafts. LG contributed to the design of the study and to data acquisition and interpretation. She reviewed manuscript drafts. AM contributed to the design of the study and to data acquisition and interpretation. She reviewed manuscript drafts. FS contributed to the design of the study and to data analysis. $\mathrm{He}$ reviewed manuscript drafts. MA contributed significantly to the design of the study and to data analysis and interpretation. She drafted the initial version of the manuscript. All authors approved the final version of the manuscript.

Funding None.

\section{Compliance with ethical standards}

Conflict of interest The authors declare that they have no conflict of interest.

Human and animal rights statement All procedures performed in this study were in accordance with the ethical standards of the institutional or national research committee and with the 1964 Helsinki declaration and its later amendments or comparable ethical standards. Ethical 
approval has been granted by the Institutional Review Board of Strasbourg Medical School on June 13, 2017, \#2017-25. An extension of ethical approval was obtained by the same board for this study on May 4, 2020.

Informed consent Participants were informed that their completion of the questionnaire indicated their consent to participate in the study.

\section{References}

1. Baker DM, Bhatia S, Brown S et al (2020) Medical student involvement in the COVID-19 response. Lancet 395:1254. https ://doi.org/10.1016/S0140-6736(20)30795-9

2. Whelan A, Prescott J, Young G et al (2020) Guidance on medical students' clinical participation: effective immediately. Association of American Medical Colleges. https://lcme.org/wp-content/uploa ds/filebase/March-17-2020-Guidance-on-Mediical-Students-Clini cal-Participation.pdf. Accessed 22 Oct 2020

3. The Association of Faculties of Medicine of Canada (2020) Ten guiding principles for medical education. https://afmc.ca/sites /default/files/pdf/2020-Ten_Guiding_Principles_for_Medical_ Education_COVID_Era_en.pdf. Accessed 22 Oct 2020

4. Medical Schools Council (2020) Advice from Medical Schools Council to UK Medical schools on actions surrounding Covid-19. https://www.medschools.ac.uk/media/2620/msc-covid-19-advic e-for-uk-medical-schools.pdf. Accessed 22 Oct 2020

5. Ministère des Solidarités et de la Santé Coronavirus : foire aux questions pour les étudiants et les internes des filières médicales [Coronavirus: Frequently Asked Questions for Medical Students and Residents]. https://solidarites-sante.gouv.fr/IMG/pdf/covid -19_faq_etudiants_medicaux.pdf. Accessed 22 Oct 2020

6. Compton S, Sarraf-Yazdi S, Rustandy F, Radha Krishna LK (2020) Medical students' preference for returning to the clinical setting during the COVID-19 pandemic. Med Educ. https://doi. org/10.1111/medu. 14268

7. Kazdin AE (2000) Encyclopedia of psychology: develop-gooden. American Psychological Association, Washington

8. Dyrbye LN, Thomas MR, Shanafelt TD (2006) Systematic review of depression, anxiety, and other indicators of psychological distress among U.S. and Canadian medical students. Acad Med 81:354-373. https://doi.org/10.1097/00001888-200604000-00009

9. Finkelstein C, Brownstein A, Scott C, Lan Y-L (2007) Anxiety and stress reduction in medical education: an intervention. Med Educ 41:258-264. https://doi.org/10.1111/j.1365-2929.2007.02685.x

10. Hope V, Henderson M (2014) Medical student depression, anxiety and distress outside North America: a systematic review. Med Educ 48:963-979. https://doi.org/10.1111/medu.12512

11. Firth-Cozens J (2003) Doctors, their wellbeing, and their stress: it's time to be proactive about stress - and prevent it. BMJ 326:670-671. https://doi.org/10.1136/bmj.326.7391.670

12. Cao W, Fang Z, Hou G et al (2020) The psychological impact of the COVID-19 epidemic on college students in China. Psychiatry Res 287:112934. https://doi.org/10.1016/j.psychres.2020.112934

13. Bao Y, Sun Y, Meng S et al (2020) 2019-nCoV epidemic: address mental health care to empower society. Lancet 395:e37-e38. https ://doi.org/10.1016/S0140-6736(20)30309-3

14. Tran D (2020) Managing anxiety and stress in a time of pandemic. https://students-residents.aamc.org/attending-medical-school/artic le/managing-anxiety-and-stress-time-pandemic. Accessed 22 Oct 2020

15. Clark V (2020) Prioritizing wellness in the whirlwind of COVID19. https://students-residents.aamc.org/attending-medical-schoo 1/article/prioritizing-wellness-in-the-whirlwind-of-covid-19. Accessed 22 Oct 2020

16. Aker S, Midık Ö (2020) The views of medical faculty students in Turkey concerning the COVID-19 pandemic. J Commun Health. https://doi.org/10.1007/s10900-020-00841-9

17. Wu W, Zhang Y, Wang P et al (2020) Psychological stress of medical staffs during outbreak of COVID-19 and adjustment strategy. J Med Virol. https://doi.org/10.1002/jmv.25914

18. Lai J, Ma S, Wang Y et al (2020) Factors associated with mental health outcomes among health care workers exposed to coronavirus disease 2019. JAMA Netw Open 3:e203976-e203976. https:// doi.org/10.1001/jamanetworkopen.2020.3976

19. Ullah R, Amin S (2020) The psychological impact of COVID19 on medical students. Psychiatry Res 288:113020. https://doi. org/10.1016/j.psychres.2020.113020

20. Liang ZC, Ooi SBS, Wang W (2020) Pandemics and their impact on medical training: lessons from Singapore. Acad Med. https:// doi.org/10.1097/ACM.0000000000003441

21. Artino AR, La Rochelle JS, Dezee KJ, Gehlbach H (2014) Developing questionnaires for educational research: AMEE guide no. 87. Med Teach 36:463-474. https://doi.org/10.3109/01421 59X.2014.889814

22. Cook DA, Brydges R, Ginsburg S, Hatala R (2015) A contemporary approach to validity arguments: a practical guide to Kane's framework. Med Educ 49:560-575. https://doi.org/10.1111/ medu. 12678

23. Spielberger CD, Bruchon-Schweitzer M, Paulhan I (1993) Inventaire d'anxiété État-Trait: Forme Y. ECPA, les Éditions du centre de psychologie appliquée, Paris

24. Phillips AW, Reddy S, Durning SJ (2016) Improving response rates and evaluating nonresponse bias in surveys: AMEE guide no. 102. Med Teach 38:217-228. https://doi.org/10.3109/01421 59X.2015.1105945

25. Benjamini Y, Hochberg Y (1995) Controlling the false discovery rate: a practical and powerful approach to multiple testing. J R Stat Soc Ser B Methodol 57:289-300

26. Heinze G, Dunkler D (2017) Five myths about variable selection. Transpl Int 30:6-10. https://doi.org/10.1111/tri.12895

27. Guiberteau V, Marlat D (2020) Les étudiants inscrits dans les universités françaises en 2018-2019 [Students enrolled in French universities in 2018-2019]. Sous-direction des systèmes d'information et des études statistiques (Sies) - Ministère de l'Enseignement supérieur, de la Recherche et de l'Innovation. https://cache.media.enseignementsup-recherche.gouv.fr/ file/2020/39/6/NI_2020-03_Effectifs_universitaires_1235396.pdf. Accessed 22 Oct 2020

28. General Medical Council (2013) Supporting medical students with mental health conditions. https://www.gmc-uk.org/-/media /documents/supporting-students-with-mental-health-conditions -0816_pdf-53047904.pdf. Accessed 22 Oct 2020

29. Association of American Medical Colleges (2014) Personal wellbeing among medical students: findings from an AAMC pilot survey. https://www.aamc.org/system/files/reports/1/april2014a ib_personalwell-beingamongmedicalstudents.pdf. Accessed 22 Oct 2020

30. Ministère de l'Enseignement supérieur, de la Recherche et de l'Innovation (2019) Lancement du Centre national d'appui à la qualité de vie des étudiants en santé [Launch of the National Healthy Student Quality of Life Support Centre]. https://www. enseignementsup-recherche.gouv.fr/cid143914/lancement-ducentre-national-d-appui-a-la-qualite-de-vie-des-etudiants-en-sante .html. Accessed 22 Oct 2020

31. The Association of Faculties of Medicine of Canada (2018) Report on Mental Health Activities: focus on physician health. http://www.afmc.ca/sites/default/files/pdf/2018-AFMC_Repor t_on_Mental_Health_Activities_EN.pdf. Accessed 22 Oct 2020 
32. Dyrbye LN, Sciolla AF, Dekhtyar M et al (2019) Medical school strategies to address student well-being: a national survey. Acad Med 94:861-868. https://doi.org/10.1097/ACM.0000000000 002611

33. Sher L (2020) COVID-19, anxiety, sleep disturbances and suicide. Sleep Med 70:124. https://doi.org/10.1016/j.sleep.2020.04.019

34. Tian-CiQuek T, Tam WS, Tran B et al (2019) The global prevalence of anxiety among medical students: a meta-analysis. Int J Environ Res Public Health 16:2735. https://doi.org/10.3390/ijerp h16152735

35. Biggs A, Brough P, Drummond S (2017) Lazarus and Folkman's psychological stress and coping theory. In: Cooper CL, Quick J (eds) The handbook of stress and health: a guide to research and practice. Wiley, New York

36. Fares J, Al Tabosh H, Saadeddin Z et al (2016) Stress, burnout and coping strategies in preclinical medical students. North Am J Med Sci 8:75-81. https://doi.org/10.4103/1947-2714.177299

37. Erschens R, Loda T, Herrmann-Werner A et al (2018) Behaviourbased functional and dysfunctional strategies of medical students to cope with burnout. Med Educ Online 23:1535738. https://doi. org/10.1080/10872981.2018.1535738

38. Fontana MCP, Generoso IP, Sizilio A, Bivanco-Lima D (2020) Burnout syndrome, extracurricular activities and social support among Brazilian internship medical students: a cross-sectional analysis. BMC Med Educ 20:81-87. https://doi.org/10.1186/ s12909-020-01998-6

39. Shadid A, Shadid AM, Shadid A et al (2020) Stress, burnout, and associated risk factors in medical students. Cureus 12:e6633. https ://doi.org/10.7759/cureus.6633

40. McLaughlin KA, Nolen-Hoeksema S (2011) Rumination as a transdiagnostic factor in depression and anxiety. Behav Res Ther 49:186-193. https://doi.org/10.1016/j.brat.2010.12.006
41. Schäfer JÖ, Naumann E, Holmes EA et al (2017) Emotion regulation strategies in depressive and anxiety symptoms in youth: a meta-analytic review. J Youth Adolesc 46:261-276. https://doi. org/10.1007/s 10964-016-0585-0

42. Monteiro AMF, Santos RL, Kimura N et al (2018) Coping strategies among caregivers of people with Alzheimer disease: a systematic review. Trends Psychiatry Psychother 40:258-268

43. Labrague LJ, McEnroe-Petitte DM, Gloe D et al (2017) A literature review on stress and coping strategies in nursing students. J Ment Health 26:471-480. https://doi.org/10.1080/09638 237.2016.1244721

44. Jeong H, Yim HW, Song Y-J et al (2016) Mental health status of people isolated due to Middle East respiratory syndrome. Epidemiol Health 38:e2016048. https://doi.org/10.4178/epih.e2016048

45. Maunder RG (2009) Was SARS a mental health catastrophe? Gen Hosp Psychiatry 31:316-317. https://doi.org/10.1016/j.genho sppsych.2009.04.004

46. United Nations Educational, Scientific and Cultural Organization (UNESCO) (2020) COVID-19 educational disruption and response. https://en.unesco.org/covid19/educationresponse. Accessed 22 Oct 2020

Publisher's Note Springer Nature remains neutral with regard to jurisdictional claims in published maps and institutional affiliations. 